\title{
Pattern of epidemics monitoring data reporting among health facilities in Nairobi City County, Kenya
}

Muturi $\mathrm{SG}^{1}$, Otieno $\mathrm{G}^{2}$, Ngatiri $\mathrm{G}^{3}$, Muhoho $\mathrm{N}^{4}$

\author{
${ }^{I}$ Tropical Institute of \\ Community Health, \\ Great Lakes University of \\ Kisumu, P.O. Box 2224- \\ 40100, Kisumu, Kenya \\ ${ }^{2}$ Department of Health \\ Management and \\ Informatics, Kenyatta \\ University, P.O. Box \\ 43844- 00100, Nairobi, \\ Kenya \\ ${ }^{3}$ Great Lakes University \\ of Kisumu, P.O. Box \\ 54533-00200, Nairobi, \\ Kenya \\ ${ }^{4}$ School of Medicine, \\ Kenyatta University, \\ P.O. Box 43844-00100, \\ Nairobi, Kenya
}

Corresponding author:

Mr. Samuel G. Muturi,

Tropical Institute of

Community Health,

Great Lakes University of

Kisumu. P.O. Box 2224

- 40100, Kisumu, Kenya.

Email:muturisg09@

yahoo.com

\section{Abstract}

Background: Weekly epidemic monitoring data reporting was adopted in Kenya after the Ministry of Health embraced Integrated Disease Surveillance and Response (IDSR) strategy from WHO - Africa region to facilitate timely detection and response to disease outbreak. The government has a reporting target of $80 \%$ but this has not been achieved by many counties including Nairobi County. Underreporting put counties at risk of untimely outbreak detection which can, in turn result in epidemic menace. There is no adequate data to explain under-reporting in Nairobi County. The aim of this study was to determine the factors associated with poor epidemic monitoring data reporting among health facilities in Nairobi County.

Methods: This was a cross-sectional analytical study targeting 318 health facilities in Nairobi County, Kenya. A stratified sample of 169 health facilities was selected using simple random. Health facility records were checked for compliance to quarterly submission of reports. A self-administered questionnaire was administered to data focal persons in the health facility in order to understand background characteristics of the participants, data transmission methods at each health facility, adherence to policies, personnel and availability of data collections tools. Data was analyzed using SPSS version 17.0. Relationships among study variables were tested using Chi-square, $(\mathrm{P}<0.05)$.

Results: Complete reporting was recoded in a total of $47 \%$ of the health facilities within the period under review, $36 \%$ partial reporting and $17 \%$ had not reported at all. Complete reporting was higher in public facilities (74\%) than in private facilities $(40.8 \%)$. Non-reporting was similarly higher in private facilities (25\%) particularly the clinics (33\%). Among institution related factors, supervision, presence of data focal person in a health facility and data transmission methods were significantly associated with poor data reporting $(\mathrm{P}<0.001)$. Training and awareness of data reporting days were important individual factors which were significantly associated with poor reporting $(\mathrm{P}<0.001)$. Rapid response to disease outbreaks is important for control of the disease and its spread to other regions. However, with only $47 \%$ of the health facilities in Nairobi County complying with the data reporting requirements, the City is at risk of delayed response in case such outbreak occurred. There is need to streamline the system to realize, exceed and maintain the government epidemic monitoring data reporting target rate of $80 \%$.

Key words: Disease, Epidemics, Reporting

\section{Introduction}

Reporting of priority diseases and conditions is one of core functions of disease surveillance strategy [1]. Other than information it provides on disease pattern, reporting also provides early warning of epidemics, hence it elicits timely detection and response to outbreaks $[2,3]$. Selection of priority diseases and the laws guiding their reporting differ from country to country [4]. Currently reporting of priority diseases is done in more than 40 countries in Africa, Kenya included [5].

The concept of weekly epidemic monitoring data reporting in Kenya was initiated after the government embraced integrated Disease Surveillance and Response (IDSR) strategy in 1998 [6]. It was after realization that the existing disease surveillance systems were not effectively measuring health impact of diseases intervention programs and hence late detection and response to epidemics [7]. Kenya has 41 diseases and conditions that are required to be reported and 23 of them are reported on weekly basis, to the Disease Surveillance and Response Unit (DSRU) via sub- 
county disease surveillance office [6]. The data report must be in DSRU office by Wednesday of every week from all health facilities [8].

The population of Nairobi City which is the Capital City of the Republic of Kenya and an urban County is about 3,200,000 according to 2009 census. The City also houses some of the largest informal human settlements in Africa thus high potentials for epidemic outbreaks [9, 10]. For example cholera outbreaks are not uncommon in Kenya. In 2009, Kenya reported 11,769 cases and 274 deaths throughout the country, Nairobi included [11, 12]. In 2014 and 2015 Nairobi was second from Wajir County (1824 and 2426 cases respectively) with highest number of cholera cases among 22 counties that recorded yet another outbreak in Kenya [13]. Majority of cholera cases recorded in Nairobi came from informal settlements areas. In 2016 three yellow fever patients who were migrants from Angola were detected in Nairobi, one died and the other two survived [14]. These underscores the importance of timely reporting of epidemic monitoring data. Nevertheless, the rates of epidemic monitoring data reporting in Nairobi has been low and below government target of $80 \%$ [15].

The reason behind under reporting is not clearly known and there is no data to explain the low reporting rate. Studies done in rural areas and their results cannot be generalized to represent urban and counties like Nairobi with different urban characteristics.

Objective: This study aims at determining the pattern and the factors associated with low rates of epidemic monitoring data reporting in Nairobi County.

\section{Materials and Methods}

Site of study: The study was done in Nairobi County, (The Capital City of The Republic of Kenya) with geographical coverage of $696 \mathrm{~km}^{2}$. The County is subdivided into nine sub-counties. Health facilities are unevenly distributed in the sub-counties [12]. A sample size of 169 health units was included in this study; a health facility was included if it was offering curative services. One stratum of health facilities contained public units and the other had private health units.

The In-charge of selected health facility and disease surveillance coordinator were interviewed to provide qualitative data for the validation of quantitative data. The study borrowed extensively from Herzberg's motivationhygiene theory in study variables development [16]. Quantitative data was analyzed by use of SPSS version 17.0 computer software. Chi-square test was used to test relationship between different study variables with the outcome variable. Permission to collect data and consent from individual respondent was obtained appropriately before data collection.

\section{Results}

Out of 169 health facilities sampled 92\% returned questionnaires for analysis, $83 \%$ of whom had submitted data at least once for the 13 weeks under review. Complete reporting was recorded in $47 \%$ of the health facilities, and 36\% for partial reporting (Figure 1).

In respect to health facilities ownership, $74 \%$ and $40.8 \%$ of public and private health facilities had done complete reporting respectively. Twenty percent of private facilities did not report at all compared to $7 \%$ of public facilities. Thirty-four percent of individuals owned private facilities had done complete reporting unlike $52 \%$ of them under corporate ownership. Subcounty hospitals had $75 \%$ complete reporting compared to clinics at $27 \%$ (Table 1 ).

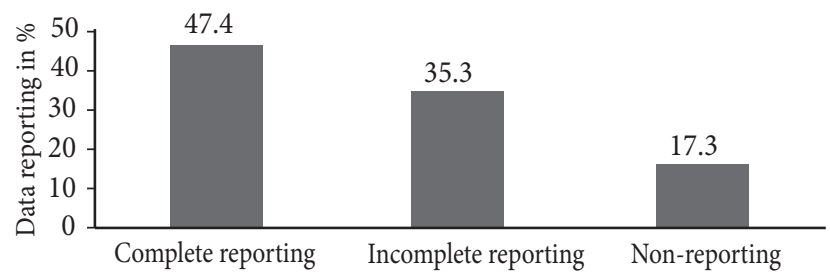

Figure 1: Data reporting among health facilities $(\mathrm{n}=156)$

Table 1: Data reporting by type and level of health facilities

\begin{tabular}{|c|c|c|c|c|}
\hline \multirow{2}{*}{$\begin{array}{l}\mathrm{H} / \text { facility } \\
\text { type }\end{array}$} & \multicolumn{3}{|c|}{ Reporting level } & \multirow[b]{2}{*}{ Total } \\
\hline & $\begin{array}{l}\text { Complete } \\
\text { reporting }\end{array}$ & $\begin{array}{l}\text { Partial } \\
\text { reporting }\end{array}$ & $\begin{array}{l}\text { Non- } \\
\text { reporting }\end{array}$ & \\
\hline $\begin{array}{l}\text { Private* } \\
\text { (Individual) }\end{array}$ & $29(34 \%)$ & $34(41 \%)$ & $20(25 \%)$ & $83(100 \%)$ \\
\hline $\begin{array}{l}\text { Private* } \\
\text { (Corporate) }\end{array}$ & $22(52 \%)$ & $15(36 \%)$ & $5(12 \%)$ & $42(100 \%)$ \\
\hline Public & $23(74 \%)$ & $6(19 \%)$ & $2(7 \%)$ & $31(100 \%)$ \\
\hline \multirow{2}{*}{$\begin{array}{l}\mathrm{H} / \text { facility } \\
\text { level }\end{array}$} & \multicolumn{3}{|c|}{ Reporting level } & \\
\hline & $\begin{array}{l}\text { Complete } \\
\text { reporting }\end{array}$ & $\begin{array}{l}\text { Partial } \\
\text { reporting }\end{array}$ & $\begin{array}{l}\text { Non- } \\
\text { reporting }\end{array}$ & Total \\
\hline Dispensaries & $26(54 \%)$ & $17(35 \%)$ & $5(11 \%)$ & $48(100 \%)$ \\
\hline $\mathrm{H} /$ centres & $27(60 \%)$ & $14(31 \%)$ & $4(9 \%)$ & $45(100 \%)$ \\
\hline Clinics & $15(27 \%)$ & $22(40 \%)$ & $18(33 \%)$ & $55(100 \%)$ \\
\hline $\begin{array}{l}\text { Sub-county } \\
\text { hospitals }\end{array}$ & $6(75 \%)$ & $2(25 \%)$ & $0(0 \%)$ & $8(100 \%)$ \\
\hline
\end{tabular}

*Private facilities are grouped into those owned by individuals and those under corporate ownership.

The methods used to transmit epidemics monitoring data reporting information to the centers were mobile phone $(31 \%)$ with $53 \%$ complete reporting via SMS messages, hand delivery (45\%) with $47 \%$ complete reporting and $7 \%$ e-mail delivery. Among facilities that had complete reporting, 53\% were using SMS/ phone call while $41 \%$ were using hand delivery (handpicked paper forms) methods. (Figure 2). There was significant difference between methods of data transmission $(\mathrm{P}<0.001)$. 


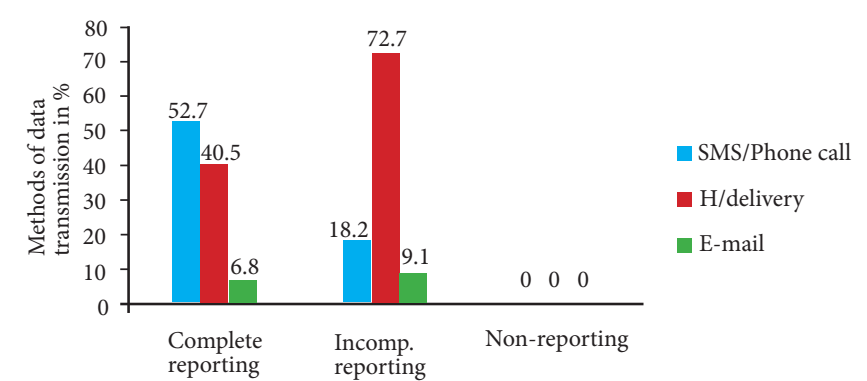

Figure 2: Methods of data transmission and reporting status

Individual factors: Among individual factors used to determine pattern of reporting was age, gender, education status of data focal person, awareness of data reporting days and training. Facilities with female data focal person reported higher complete reporting rate $(52 \%)$ than them with male counterpart (41\%). Facilities where data focal persons had secondary and college level of education reported higher level of complete reporting ( $43 \%$ and $50 \%$ respectively) than them with university education $(36 \%)$ (Table 2).

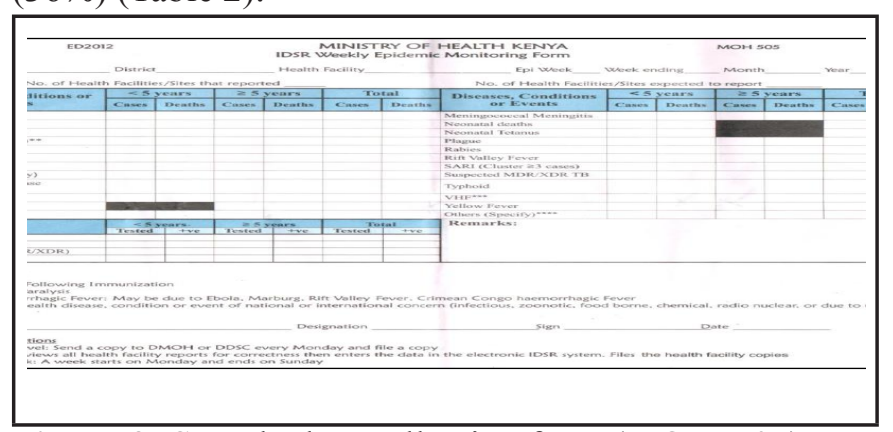

Figure 3: Sample data collection form (MOH, 505)

Data handlers were examined on their knowledge on data reporting days, where $68 \%$ knew the correct days of reporting and among them $57 \%$ had done complete reporting against $26 \%$, who were not sure of the precise days of reporting. Training on data reporting among data
Table 2: Demographic information of respondents $(\mathrm{n}=156)$

\begin{tabular}{lllll}
\hline \multirow{2}{*}{$\begin{array}{l}\text { Education } \\
\text { level }\end{array}$} & \multicolumn{3}{c}{ Reporting level } & \\
\cline { 2 - 4 } & $\begin{array}{l}\text { Complete } \\
\text { reporting }\end{array}$ & $\begin{array}{l}\text { Partial } \\
\text { reporting }\end{array}$ & $\begin{array}{l}\text { Non- } \\
\text { reporting }\end{array}$ & Total \\
\cline { 2 - 5 } O-Level & $16(43 \%)$ & $10(27 \%)$ & $11(30 \%)$ & $37(100 \%)$ \\
College & $53(50 \%)$ & $39(37 \%)$ & $13(13 \%)$ & $105(100 \%)$ \\
University & $5(36 \%)$ & $6(43 \%)$ & $3(21 \%)$ & $14(100 \%)$ \\
Total & $74(47 \%)$ & $55(35 \%)$ & $27(18 \%)$ & $156(100 \%)$ \\
\cline { 2 - 4 }
\end{tabular}

Age of respondents and level of data reporting

\begin{tabular}{lllll} 
& \multicolumn{4}{c}{ Reporting level } \\
\cline { 2 - 5 } $\begin{array}{l}\text { Age in } \\
\text { years }\end{array}$ & $\begin{array}{l}\text { Complete } \\
\text { Reporting }\end{array}$ & $\begin{array}{l}\text { Partial } \\
\text { Reporting }\end{array}$ & $\begin{array}{l}\text { Non- } \\
\text { Reporting }\end{array}$ & Total \\
\cline { 2 - 5 } $20-29$ & $12(33 \%)$ & $17(47 \%)$ & $7(20 \%)$ & $36(100 \%)$ \\
$30-39$ & $40(51 \%)$ & $26(33 \%)$ & $12(16 \%)$ & $78(100 \%)$ \\
$40-49$ & $13(43 \%)$ & $11(37 \%)$ & $6(20 \%)$ & $30(100 \%)$ \\
$50-59$ & $9(75 \%)$ & $1(8 \%)$ & $2(17 \%)$ & $12(100 \%)$ \\
Total & $74(47 \%)$ & $55(35 \%)$ & $27(18 \%)$ & $156(100 \%)$ \\
\hline
\end{tabular}

Sex of data focal persons and level of reporting

\begin{tabular}{lllll} 
& \multicolumn{3}{c}{ Reporting level } & \multirow{2}{*}{ Total } \\
\cline { 2 - 5 } Sex & $\begin{array}{l}\text { Complete } \\
\text { reporting }\end{array}$ & $\begin{array}{l}\text { Partial } \\
\text { reporting }\end{array}$ & $\begin{array}{l}\text { Non- } \\
\text { reporting }\end{array}$ \\
\cline { 2 - 5 } Male & $29(41 \%)$ & $25(36 \%)$ & $16(23 \%)$ & $70(100 \%)$ \\
Female & $45(52 \%)$ & $30(35 \%)$ & $11(13 \%)$ & $86(100 \%)$ \\
\cline { 2 - 5 } Total & $74(47 \%)$ & $55(35 \%)$ & $27(18 \%)$ & $156(100 \%)$ \\
\hline
\end{tabular}

handlers was reported in $67 \%$ of facilities and among those facilities $60 \%$ had done complete reporting compared to $21 \%$ of facilities that had not trained. Having been trained and aware of data reporting days was significantly associated with reporting $(\mathrm{P}<0.001)$ (Table 3$)$.

Table 3: Relationship between different variables and level of reporting $(\mathrm{df}=2)$

\begin{tabular}{|c|c|c|c|c|c|c|c|}
\hline \multicolumn{8}{|c|}{ Data reporting level in $\mathrm{H} /$ facilities } \\
\hline \multicolumn{2}{|c|}{ Variables } & $\begin{array}{l}\text { Complete } \\
\text { reporting }\end{array}$ & $\begin{array}{l}\text { Partial } \\
\text { reporting }\end{array}$ & $\begin{array}{l}\text { None- } \\
\text { reporting }\end{array}$ & Total & $X^{2}$ & P-value \\
\hline Training/ & Done & $63(60 \%)$ & $30(29 \%)$ & $11(11 \%)$ & $104(100 \%)$ & & \\
\hline Sensitization & Not done & $11(21 \%)$ & $25(48 \%)$ & $16(31 \%)$ & $52(100 \%)$ & 23.16 & $\mathrm{P}<0.001$ \\
\hline \multirow{2}{*}{ Focal person } & Present & $69(66 \%)$ & $25(28 \%)$ & $5(6 \%)$ & $99(100 \%)$ & \multirow{3}{*}{59.52} & \multirow{3}{*}{$\mathrm{P}<0.001$} \\
\hline & Not present & $5(9 \%)$ & $30(53 \%)$ & $22(38 \%)$ & $57(100 \%)$ & & \\
\hline Data & Present & $52(59 \%)$ & $30(34 \%)$ & $6(7 \%)$ & $88(100 \%)$ & & \\
\hline Reporting policy & Not present & $22(32 \%)$ & $25(37 \%)$ & $21(31 \%)$ & $68(100 \%)$ & \multirow[t]{2}{*}{18.69} & \multirow[t]{2}{*}{$\mathrm{P}<0.001$} \\
\hline Socialization & Present & $66(56 \%)$ & $42(35 \%)$ & $10(9 \%)$ & $118(100 \%)$ & & \\
\hline opportunity & Not present & $8(21 \%)$ & $13(34 \%)$ & $17(45 \%)$ & $38(100 \%)$ & \multirow[t]{2}{*}{29.22} & \multirow[t]{2}{*}{$\mathrm{P}<0.001$} \\
\hline \multirow{2}{*}{ Team work } & Present & $64(63 \%)$ & $28(27 \%)$ & $10(10 \%)$ & $102(100 \%)$ & & \\
\hline & Not present & $10(19 \%)$ & $27(50 \%)$ & $17(31 \%)$ & $54(100 \%)$ & \multirow{2}{*}{29.24} & \multirow[t]{2}{*}{$\mathrm{P}<0.001$} \\
\hline \multirow{2}{*}{ Supervision } & Present & $68(67 \%)$ & $29(28 \%)$ & $5(5 \%)$ & $102(100 \%)$ & & \\
\hline & No & $6(11 \%)$ & $26(48 \%)$ & $22(41 \%)$ & $54(100 \%)$ & \multirow{3}{*}{$\begin{array}{l}53.07 \\
29.05\end{array}$} & $\mathrm{P}<0.001$ \\
\hline Awareness of & Aware & $61(57 \%)$ & $38(36 \%)$ & $7(7 \%)$ & $106(100 \%)$ & & \multirow{2}{*}{$\mathrm{P}<0.001$} \\
\hline reporting day & Not aware & $13(26 \%)$ & $17(34 \%)$ & $20(40 \%)$ & $50(100 \%)$ & & \\
\hline
\end{tabular}


Institutional factors: Variables like presence of data focal person in the facility, supervision, teamwork and presence of data reporting policy were some of institutional related factors used to determine reporting pattern. Facilities that had data focal persons were $63 \%$ and among them $66 \%$ had done complete reporting unlike $9 \%$ of facilities that had no data focal person. Five percent of facilities with data focal person did not report at all.

Supervision of data reporting was reported in $65 \%$ of facilities and its frequency was monthly $(60 \%)$, ad hock $(17 \%)$ and quarterly. Facilities that practice supervision $67 \%$ had done complete reporting, against $11 \%$ of those with no supervision.

Among facilities visited, $56 \%$ had data reporting policies. Among them 57\% said their policies guide in both weekly outbreak monitoring data and monthly data reporting while the rest said policies deals with monthly reportable data only. Among facilities with data policies, $59 \%$ had done complete reporting against $32 \%$ of them without. None $(0 \%)$ of the health facilities that reported to have data reporting policies had a written document on the same but relies on meeting resolutions recorded in form of minutes. Data reporting policies was significantly associated with reporting $(\mathrm{P}<0.001)$.

Teamwork and socialization opportunities among staff were observed in $66 \%$ and $76 \%$ of facilities respectively. Major socialization opportunities mentioned were meals breaks $(40 \%)$, staff welfare meetings (26\%) and religious meetings (10\%). Facilities where socialization opportunities exist $56 \%$ had done complete reporting against $21 \%$ of them that did not have. Among facilities that reported teamwork $63 \%$ had done complete reporting unlike $19 \%$ of facilities reported no teamwork. Activities mentioned that demonstrated teamwork was notifying data focal person or facility incharge when a reportable disease is suspected (28\%), and involvement in facility meetings (35\%). Both teamwork and socialization opportunities were important factors significantly associated with reporting $(\mathrm{P}<0.001)$.

Other institutional factors examined were presence of working office for data handler and shortage of staffs in a health facility. Office for data handlers existed in $69 \%$ of facilities visited while $67 \%$ reported shortage of data staff in their facilities. Forty percent of facilities that reported staff shortage had done complete reporting against $52 \%$ of facilities without staff shortage. Statistically both staff shortage and presence of data handler's office were not significantly associated with reporting $(\mathrm{P}<0.202$, $\mathrm{P}=0.217$ respectively).

Data collection tool $(\mathrm{MOH}, 505)$ was available only in $90 \%$ of facilities where $82 \%$ had paper forms (hardcopies) and $8 \%$ had both soft and hardcopies. Data reporting reference materials identified in health facilities were reportable diseases list, standard case definition posters and Disease Surveillance Technical Guidelines (DSTG) at 48, 68 and 14 percent respectively.

Fifty-seven percent of facilities had a computer while $88 \%$ of data handlers interviewed had a mobile phone and $85 \%$ of them said the gadget was personal. When asked if they can agree to use personal phone in data reporting if facilitated, all of them (100\%) accepted.

\section{Discussion}

Timely epidemics' reporting is important in order to avert their spread to other regions promptly. However, the findings in this study indicate unpreparedness of the City of Nairobi to prevent the spread of such outbreaks. Complete epidemic monitoring data reporting among health facilities was only $47.5 \%$ against the $80 \%$ National target rate. Nairobi is a cosmopolitan city that has high potentials of disease outbreaks [9] owing to constant human immigration from various regions in the country, internationally and the fact that it houses some of the largest informal settlements in Africa where sanitation is poor $[10,14]$.

In this study less than half (47\%) of health facilities had done complete reporting of expected data, a lower proportion than what was found in Nigeria [17] and Sudan [18] where over three quarters $(80 \%)$ of facilities had submitted their data. The rate was higher in this study than in Tanzania [19] where only 19\% of facilities had submitted their data. Further observation in this study shows the idea of data reporting was known in many health facilities for majority (83\%) of facilities had attempted to send data at least once during the period under review. However, over a third $(36 \%)$ of the said facilities did not regularly submit data or they did not submit them on. Consistency was therefore, a major challenge.

Significantly low reporting was largely recorded in private facilities than public. This is evidenced by only $40.8 \%$ of private facilities submitted all the expected data compared to $74 \%$ of public facilities. Individual owned private facilities are the worst non-reporters followed by facilities under corporate private ownership at $25 \%$ and $12 \%$ respectively. As far as the levels of facilities are concerned, clinics are the worst non-reporters (33\%) while the best reporters are sub-county hospitals (75\%).

Health facility related factors: In this study, use of mobile phones promoted higher and complete reporting while hand delivery (handpicked paper forms) method encouraged partial reporting. This was supported by over half (53\%) of facilities that had complete reporting were using mobile phones compared to $41 \%$ of facilities that were using hand delivery method. Facilities that did partial reporting, $73 \%$ were using hand delivery method against $18 \%$ of them that used mobile phones. A study in Tanzania found use of mobile phone improved data reporting timeliness significantly and in Kenya use of mobile phone in reporting had better performance compared to other methods $(\mathrm{P}<0.024)[7,20]$.

E-mail technology of communication was the least used in this study, despite existence of computers in 
$57 \%$ of the health facilities. This could be a challenge of accessibility to E-mail technology in such facilities, a factor that this study did not address. Similarly, in Iraq about three quarters $(76.6 \%)$ of health facilities that reported to have computers were not using them in reporting [21].

Both awareness of correct days of data transmission and training among data handlers were significantly associated with reporting $(\mathrm{P}<0.001)$ in this study and importantly improved reporting. This was proved by almost two thirds $(60 \%)$ of facilities reported training had done complete reporting, compared to a fifth (21\%) of those who did not have the necessary training. A similar study in Kenya established health facilities that had trained staff showed improvement in reporting $(\mathrm{P}=$ 0.017 ) than those who had no trained staff [7]. In Nigeria, inadequate knowledge on reporting was linked to poor data reporting [22].

In this study, shortage of staff had no significant association with data reporting $(\mathrm{P}<0.202)$ unlike in Sudan [18] where staff shortage was associated with poor performance while in Tanzania, [19] it was established reporting was poorly done during the period when the data focal person was on leave. The present study revealed, appointment of data focal persons in a facility with improved reporting, similar to use of mobile phone technology in reporting, however working space does not have a significant association with data reporting $\mathrm{P}<0.217$ ).

Supervision was also a significant institutional factor associated with reporting in this study $(\mathrm{P}<0.001)$. Facilities that performed supervision $65 \%$ had complete reporting as opposed to only $9 \%$ with no supervision. Besides, $41 \%$ of facilities without supervision did not report compared to $5 \%$ of facilities with supervision. Nevertheless, despite its importance supervision was infrequently done $(60 \%$ monthly, $17 \%$ ad hock, quarterly and $23 \%$ quarterly) in this study rather than on weekly basis. This is a cause of concern for timely reporting. In India [23] poor supervision was associated with poor performance of disease surveillance strategy while lack of or poorly performed supervision demoralized health workers in their performance in Tanzania [24].

In the present study, availability of data reporting policy guidelines in the facilities improved reporting. Over a half $(59 \%)$ of health facilities reported policy guidelines had complete reporting compared to a third $(32 \%)$ of facilities that did not have them. Even though presence of policies had significance in reporting, more improvement is likely to be seen if set policies guide weekly epidemic data reporting in all facilities. Currently slightly more than half $(57 \%)$ of facilities with policies that guides weekly epidemic data reporting.

In this study reference materials are widely lacking in health facilities and could be blamed on poor reporting for they ought to remind staffs on reporting. A third
(32\%) of facilities did not have a poster on reportable diseases and over three quarters $(86 \%)$ did not have Disease Surveillance Technical Guidelines manual (DSTG). Worse still is lack of data collection tool $(\mathrm{MOH}$, 505 ) in $10 \%$ of facilities, similar to findings in Nigeria [17] where lack of adequate surveillance forms was significantly associated with reporting of outbreak.

\section{Conclusions and Recommendations}

This study found lack of data reporting focal person in health facilities, lack or inadequate supervision plus insufficient utilization of mobile phone technology in data transmission are among core challenges hindering optimal data reporting in Nairobi City County and causes inconsistency in reporting which is a key problem in many health facilities.

Training, knowledge on correct days of data reporting plus lack of data collection tools ( $\mathrm{MOH}, 505)$ in some health facilities are also important factors that should not be ignored.

Corrective measures should largely be directed towards reducing partial/incomplete and non-reporting especially among private facilities and particularly clinics. Use of mobile phone technology encouraged higher and complete reporting and should be strictly encouraged as opposed to hand delivery method that supported partial/incomplete reporting. Email method is significantly underutilized and more investigation about its underutilization is recommended.

Training/sensitization of data focal persons promotes awareness on reporting and is encouraged in this study. Managerial factors such as supervision, appointment of data focal person in a health facility and teamwork among facility staffs are among important institution factors that need to be promoted and strictly implemented. Adherence to the above recommendations will not only enhance completeness in data reporting but will also contribute significantly to the realization of timely outbreak detection which is the core objective of public health surveillance. Weekly epidemic monitoring data requires no analysis prior to transmission and possibly that was why other demographic characteristics of data handlers were not significantly found to affect reporting.

\section{Conflict of interest}

The study was funded by the researchers and there was no conflict of interest in the carrying out of the study whatsoever.

\section{Acknowledgements}

We would like to recognize Disease Surveillance and Response Unit, in the Ministry of Health and specifically 
special thanks go Madam Caroline Maina for letting us access their archives for disease surveillance reference materials. We also register our sincere appreciation to the staff of Tropical Institute of Community Health, Great Lakes University of Kisumu for their enormous support and guidance given till the completion of this study.

\section{References}

1. MOH (Ministry of Health). Disease Surveillance and Response Technical Guidelines; Division of Disease Surveillance and Response, Ministry of Health, Nairobi 2002,1 ${ }^{\text {st }}$ ed. pg 4-5.

2. $\mathrm{MOH}$ (New Zealand). Direct Laboratory Notification of communicable diseases -National guidelines, Wellington, New Zealand, 2007, $1^{\text {st }}$ ed. pg 1-15 Available from http://www.moh.govt.nz

3. Wood C, Ngatia P, Nyakwana T, Oirere B, Rabar $B$ and Waithaka PM. Prevention and control of communicable diseases, community health, Africa Medical and Research Foundation, 2008, $3^{\text {rd }}$ ed. pg 245-259.

4. WHO-AFRO (World Health Organization- Africa region).Technical Guidelines for Integrated Disease Surveillance and Response in the African region: WHO Regional office for Africa, Disease prevention and control cluster Brazzavile Republic of Congo: 2010, $2^{\text {nd }}$ ed. pg 229.

5. ASH (Africa Strategy for Health). Integrated Disease Surveillance and Response, AFENET 2013 preconference workshop report: 2013, pg 1-12 Available from http://www.africanstrategies4health.org Accessed 29/8/2014

6. MOPHS (Ministry of Public Health and Sanitation)., Integrated Disease Surveillance and Response Technical Guidelines, Ministry of Public Health and Sanitations, Nairobi, Kenya 2012. $2^{\text {nd }}$ ed pg 1-18.

7. Njuguna, C, Onsongo JK, Nzioka CM and Mutonga D. Factors determining performance of integrated disease surveillance strategy in Kenya. Int J Inf Dis. 2010; 14 (Suppl 1): e2-e190.

8. MOH (Ministry of Health). Standard case definition for priority diseases in Kenya: Integrated disease surveillance and response-Nairobi Kenya, 2003, $1^{\text {sted.Pg 4-5. }}$

9. WHO., Communicable disease risk assessment and intervention: Post-election emergencyKenya, Communicable disease working group on emergencies, WHO office-Kenya 2008, pg 1-9 Available from http://www.who.int/neglected diseases/diseasecontrol_emergencies/EPR_ DCE_2008_1rr\%20.pdf Accessed 5 ${ }^{\text {th }} / 6 / 2014$

10. WHO. Global task force on cholera control report, Cholera control profile: Kenya, 2010, pg 1-2 available from http://www.who.int/cholera/countries/ KenyaCountryProfile2010.pdf Accessed 29/4/2013
11. Njeru I. Communicable Disease Burden (Epidemiological/data trends) and Interventions, Kenya, 2009 to 2012, Division of Disease Surveillance and Response Kenya Ministry of Public Health \& Sanitation, 2013, A report of the First East African Community Epidemiological Symposium Available from http://www.eaphln-ecsahc.org/ kenya/?wpfb_dl=29 Accessed 18/10/15

12. Loharikar AE, Briere M, Ope D, Langat I, Njeru L. et al. A national cholera epidemic with high case fatality rates - Kenya 2009. J Infect Dis. 2013; 208 (Suppl 1): 69-77.

13. George G, Rotich J, Kigen H, Catherine K, Waweru B, et al. Notes from the field: ongoing cholera outbreak - Kenya, 2014-2016. Morb Mortal Wkly Rep. 2016; 65:68-69. DOI: http://dx.doi.org/10.15585/mmwr. mm6503a7.

14. IHW (Interhealth Worldwide)., Yellow fever cases in Kenya, InterHealth Worldwide, International Health Centre, 63 - 67 Newington Causeway, London, newsletter, 2016 ; Available from https://www. interhealthworldwide.org/home/health-resources/ health-alerts/2016/march/18/yellow-fever-cases-inkenya/Accessed $10^{\text {th }} / 3 / 17$

15. MOH (Ministry of Health)., Weekly epidemiological bulletin, week 14, Division of disease surveillance and response, Nairobi 2013; pg 9-20.

16. Ayah R. "Health services management" Introduction to public health, Colourprint Limited, 2011, $1^{\text {st }}$ ed. pg 238-244.

17. Dairo MD, Bamidele JO and Adebimpe WO. Disease surveillance and reporting in two Southwestern states in Nigeria: Logistic challenges and prospects. Department of Epidemiology and Medical Statistics, University of Ibadan, Ibadan, Oyo State, Nigeria. J Pub Health Epidem. 2010; 2 (6): 125-129.

18. Sahal NH. Assessment of communicable diseases surveillance system in Khartoum state, Sudan: University of Southern Denmark, Publications of the Unit for Health Promotion Research, Series A 2011; No 3.

19. Rumisha SF, Mboera LEG, Senkoro KP, Gueye $\mathrm{D}$ and Mmbuji PK. Monitoring and evaluation of integrated disease surveillance and response in selected districts in Tanzania. Tanzania Health Res. Bull. 2007; 9 (1): 1-11.

20. Pascoe I, Lungo J, Kaasboll J and Koleleni I. Collecting integrated disease surveillance and response data through mobile phones; Paul Cunningham and Miriam Cunningham (Eds), IIMC International Information Management Corporation, 2012: 1ST-Africa 2012 Conference Proceedings 
21. Al-jawadi AA and Al-neami MA. Assessment of infectious diseases surveillance system in Mosul, Iraq. Dohuk Med J. 2008; 2 (1): 132-133.

22. Bawa SB, Olumide EA and Umar US. The knowledge, attitude and practices of the reporting of notifiable diseases among health workers in Yobe State, Nigeria. Afr J Med Sci. 2003; 32(1): 4953. Available from, http://www.ncbi.nlm.nih.gov/ pubmed/15030066. accessed 30/7/2012

23. Phalkey RK, Shukla S, Shardul S, Ashtekar N, Valsa S, Awate P and Marx M. Assessment of the core and support functions of the Integrated Disease Surveillance systems in Maharashtra, India. BMC Public Health 2013, Available from http://www. biomedcentral.com/1471-2458/13/575. Accessed 22/12/13

24. Manongi RN, Marchant TC and Bygbjerg IC. Improving motivation among primary health care workers in Tanzania: a health worker perspective: Human Resource for Health 2006; BioMed Central Ltd 2006. 